\title{
Effectiveness of Different Techniques on the Seismic Retrofitting of Existing RC Framed Buildings in Saudi Arabia
}

\author{
Ayed Eid Alluqmani* \\ Department of Civil Engineering, Islamic University in Madinah, Saudi Arabia
}

DOI: $10.36348 /$ sjce.2020.v04i07.002 $\quad$ | Received: 09.09.2020 | Accepted: 17.09.2020 | Published: 19.09 .2020

*Corresponding author: Ayed Eid Alluqmani

\section{Abstract}

In this research, finite elements analysis is utilized, using SAP2000, to study the effectiveness of different techniques on the seismic retrofitting of existing reinforced concrete framed structures. The models are considered for reinforced concrete framed structures; and seismic evaluation is conducted. These models represent typical structures that were designed and constructed before and after the current Saudi Building Code, SBC-2007. The seismic evaluation was conducted using SAP2000 Program. This study focuses on performance based design of three multi-story RC framed buildings in Madinah, Saudi Arabia, subjecting them to monotonically increasing lateral forces with an invariant height wise distribution until the preset performance level (target displacement) is reached. Considering the deficiencies indicated in analysis, these buildings are redesigned by adopting retrofitting techniques such as shear wall, bracing and column strengthening. These techniques strengthen structures to reach the targeted performance level. The results indicate the effectiveness of each technique and how applicable it is to be used for seismic retrofitting of structures in Madinah, Saudi Arabia.

Keywords: Structural-Mechanics; Structural-Analysis; Earthquake-Engineering; Structural-Dynamics; SeismicAnalysis; Seismic-Design.

Copyright @ 2020: This is an open-access article distributed under the terms of the Creative Commons Attribution license which permits unrestricted use, distribution, and reproduction in any medium for non-commercial use (NonCommercial, or CC-BY-NC) provided the original author and source are credited.

\section{INTRODUCTION}

Concrete structures, and ribbed-slab building systems having wide shallow members, are commonly used in the Kingdom of Saudi Arabia, KSA; where these members should be analyzed and design against both flexural and shear strengths [1-3]. This research focuses on the seismic retrofitting of concrete structures in Saudi Arabia. Enhancing structural performance under potential earthquakes is of great importance to save lives and resources. Structural building Codes are exposed to frequent updates and development in order to consider any new hazards that were not previously considered and/or discussed in details [4-6]. There are many techniques can be utilized in order to enhance the seismic performance of existing structures, that were designed before the release of the Saudi Building Code (SBC-2007) [7], which addressed the seismic loads in different regions of the Kingdom of Saudi Arabia. Instead of increasing the dimensions and/or reinforcements of the structural elements, it is necessary required to add bracings to the structures and using some dampers to provide damping and/or stiffness to the structures. In this research study, finite element (FE) analysis is utilized, using SAP2000 Program, to study the effectiveness of different techniques on the seismic retrofitting of reinforced-concrete structures. Three structural models are considered for reinforced-concrete framed structures. Earthquake loads are carefully modeled so as to assess the real behavior of structure with a clear understanding that damage is expected but it should be regulated. The recent advent of performance based design has brought the nonlinear static pushover analysis procedure to the forefront [812]. Pushover analysis is a static, nonlinear procedure in which the magnitude of the structural loading is incrementally increased in accordance with a certain predefined pattern. With the increase in the magnitude of the loading, weak links and failure modes of the structure are identified. The loading is monotonic with the effects of the cyclic behavior and load reversals being estimated by using a modified monotonic forcedeformation criteria and with damping approximations. Static pushover analysis is an attempt by the structural engineering profession to evaluate the real strength of the structure and it promises to be a useful and effective tool for performance based design $[13,14]$. This study focuses on performance based design of three multistory reinforced-concrete framed buildings in 
Madinah, Saudi Arabia, subjecting them to monotonically increasing lateral forces with an invariant height wise distribution until the preset performance level (target displacement) is reached. Considering the deficiencies indicated in analysis, these buildings are redesigned by adopting retrofitting techniques such as shear wall, bracing and column strengthening. These techniques strengthened structures to reach the targeted performance level.

\section{Description of the buildings}

This research portrays the design earthquake resistant retrofit technique and static results by SAP2000 for four-storey reinforced concrete building (Faculty of Engineering -E1 building) which is located at Islamic University in Medina. Figure 1 shows the elevation and pictorial view of the building; whereas Figure 2 illustrates the structural plan (XY-Axis in $\mathrm{mm}$ ) of the building.

\section{Analysis of buildings}

This study focuses on performance based seismic design (PBSD) of high rise buildings of commercial and residential area of the Madinah province of Saudi Arabia. These buildings were constructed in late eighties and early nineties. The selected buildings are modeled in SAP2000 and pushover analysis (nonlinear static analysis) is done, subjecting to monotonically increasing loads until the performance level is achieved. Nonlinear static procedure is simply based on the assumption that the response of a structure can be related to the response of an equivalent single degree of freedom system. First, a model with no earthquake resistant technique was made. Figure 3 shows the SAP2000 3D Model. The 2D model is shown in Figure 4 for YZ-Axis and in Figure 5 for XZ-Axis. The simulation models of the buildings are shown for unbraced frames and braced frames. The results from analysis are shown in various hinge colours. Fourteen hinges fall in collapse point (CP) and two hinges in collapse for unbraced frame. However by providing cross bracing, the collapse point hinges and collapse hinges are shifted within the safety limits [15].

\section{Analysis results from sap 2000}

Deformation of 3D Model view is shown in Figure 6.

\section{RESULTS OF DYNAMIC ANALYSIS}

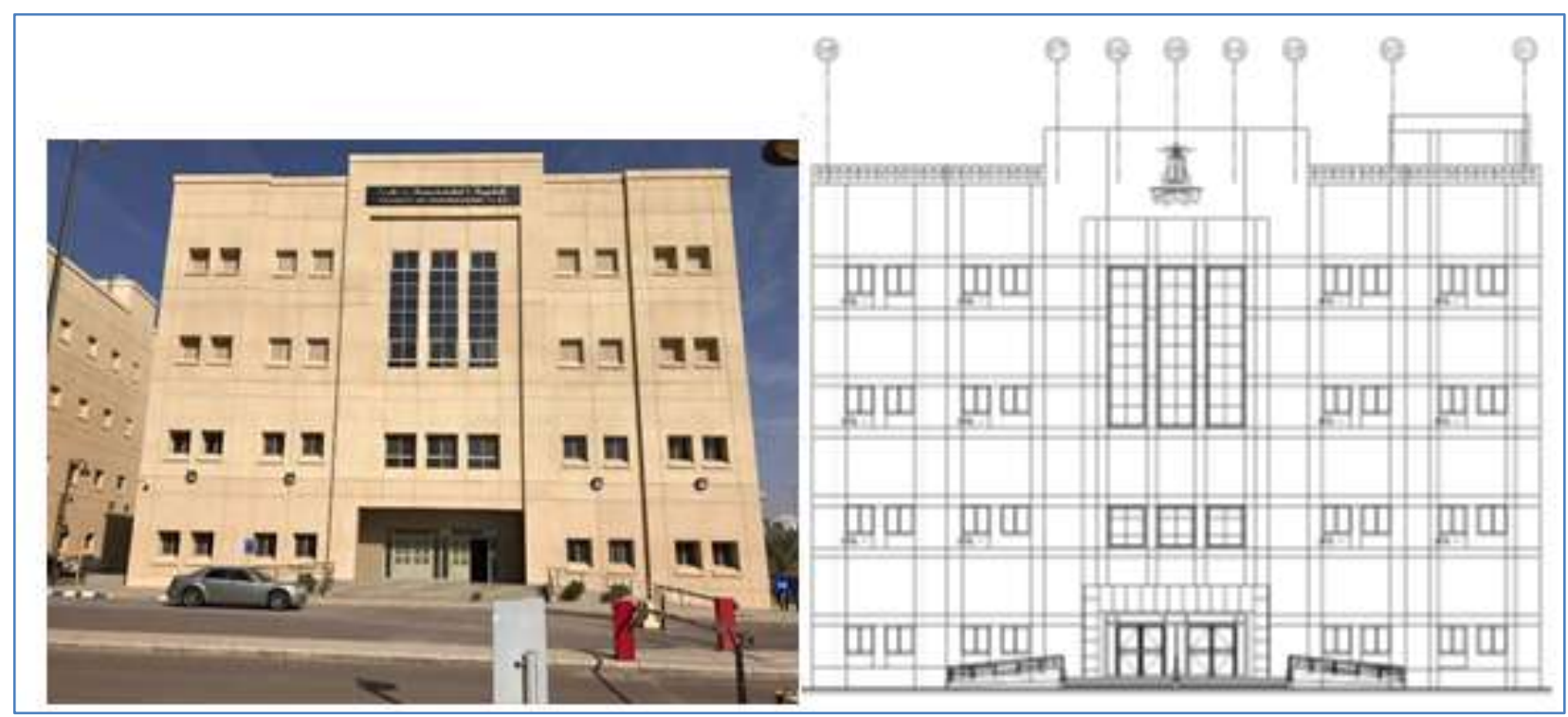

Fig-1: Elevation and Pictorial View of the Building 


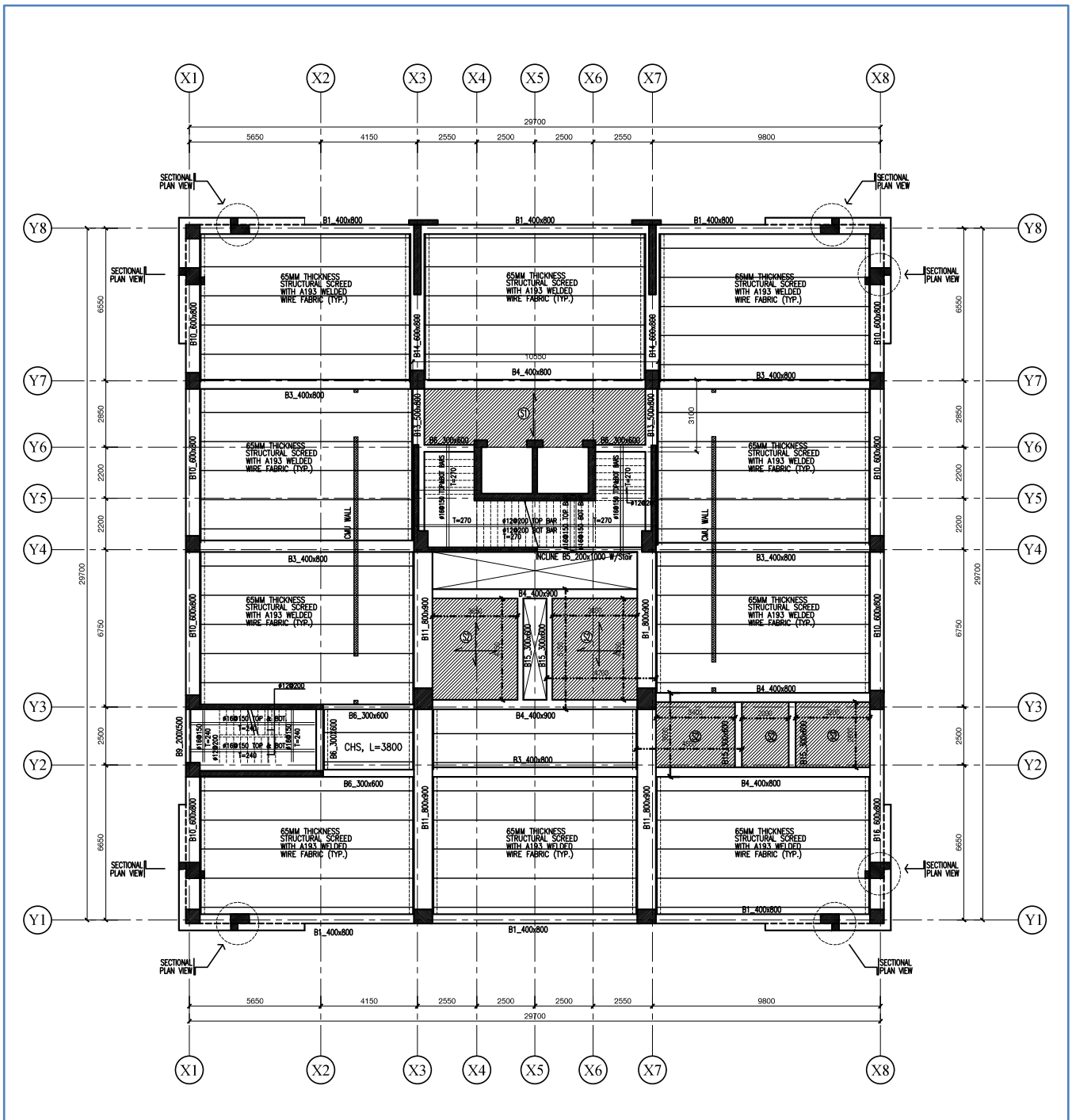

Fig-2: Plan (XY-Axis in mm) of Faculty of Engineering - E1 Building.

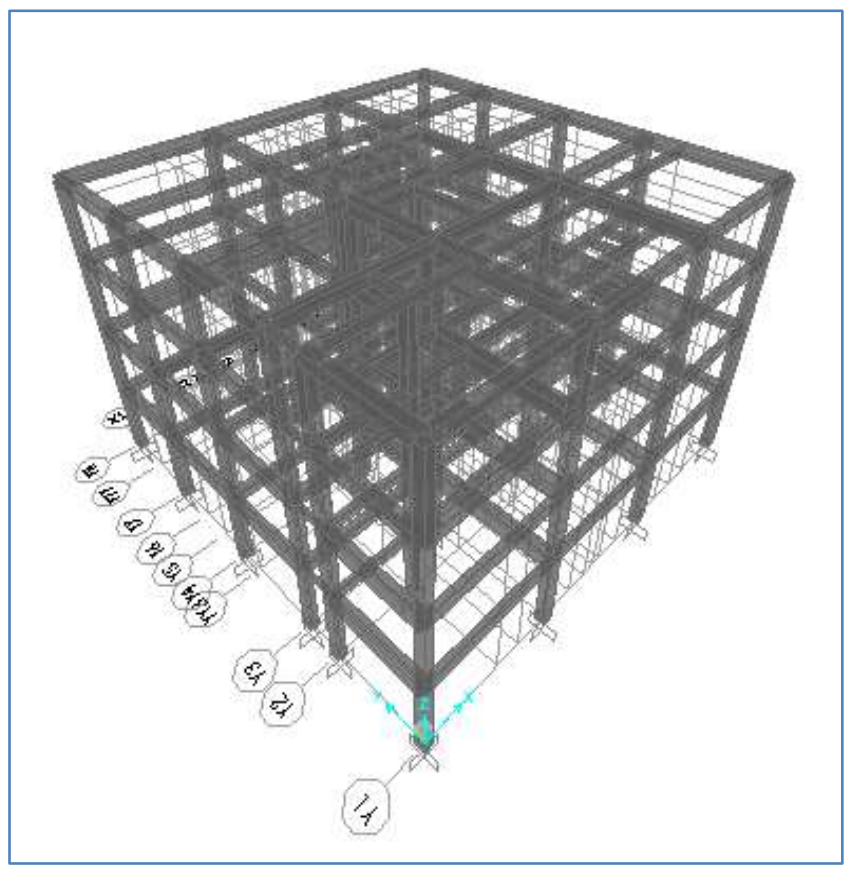

Fig-3: 3D Mode 


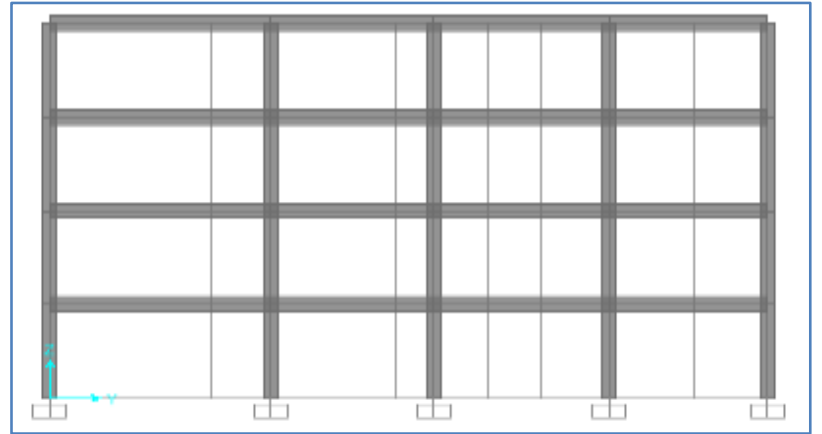

Fig-4: The 2D Model (YZ-Axis)

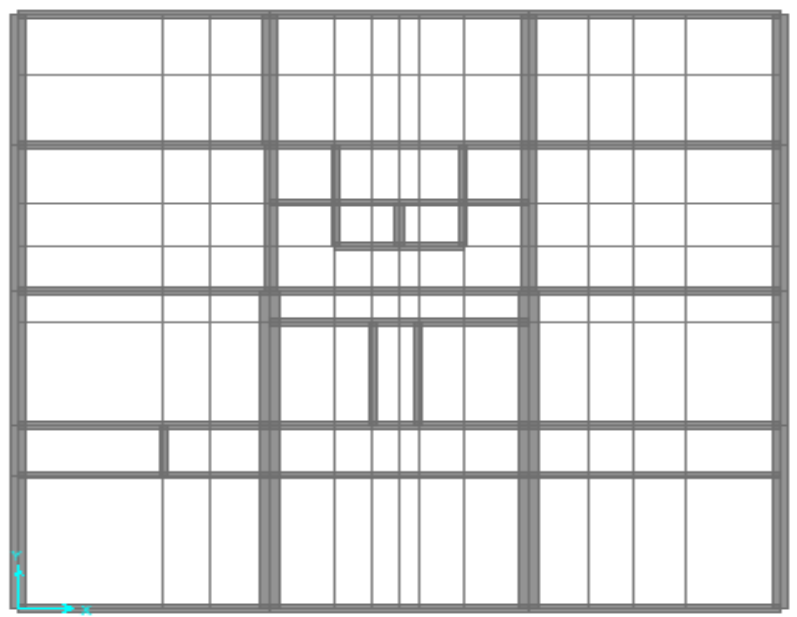

Fig-5: The 2D Model (XZ-Axis)

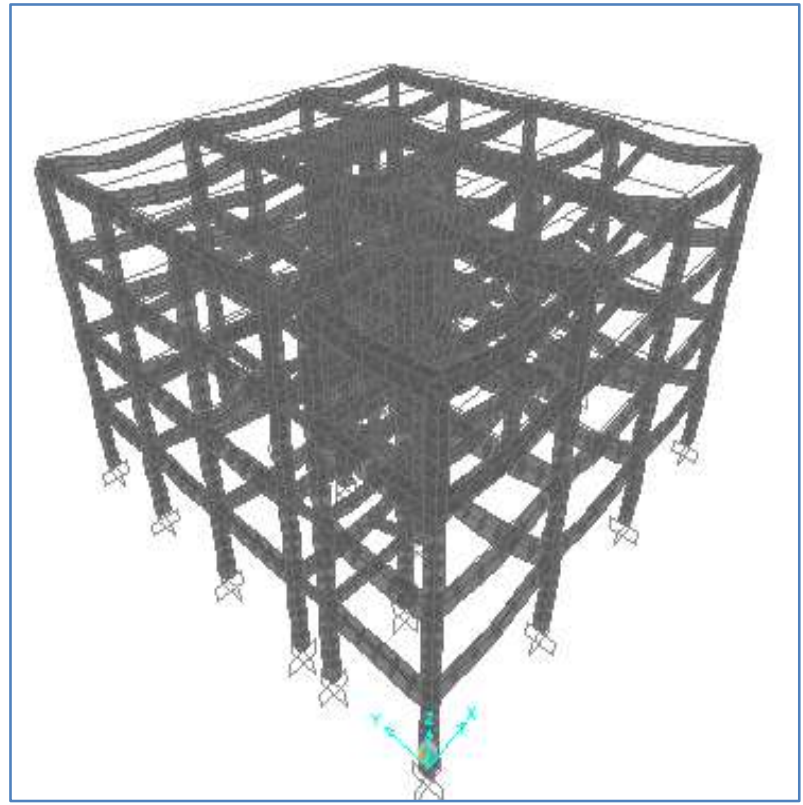

Fig-6: Deformation of 3D Model

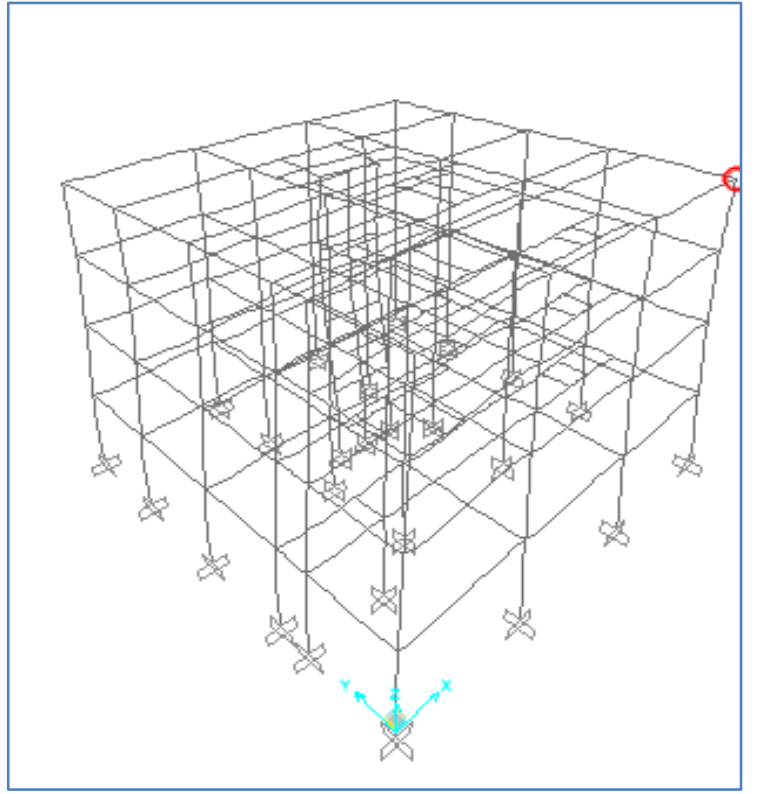

Fig-7: Deformation Shape of UBC for Frame

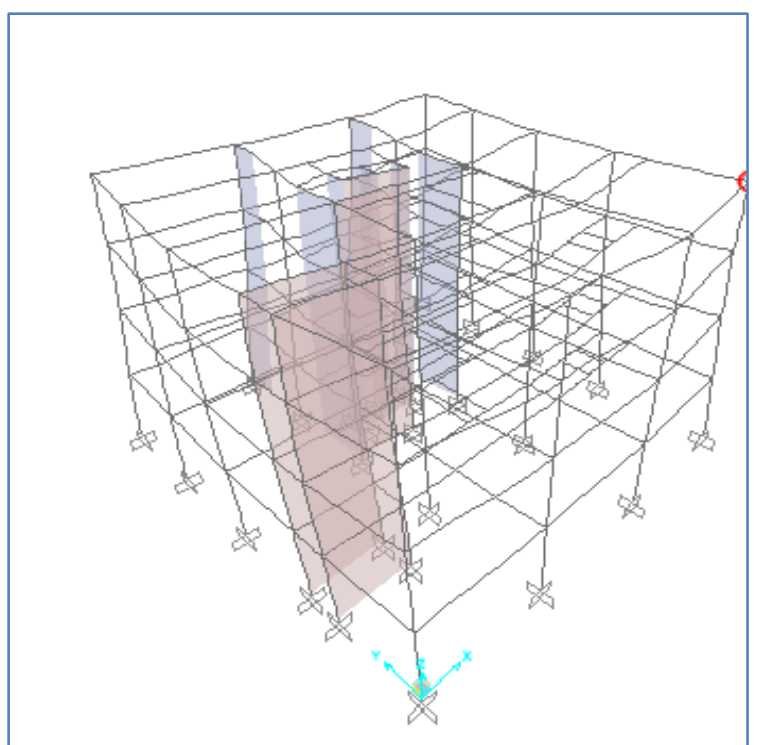

Fig-8: Deformation Shape of UBC for Frame and Shear Wall

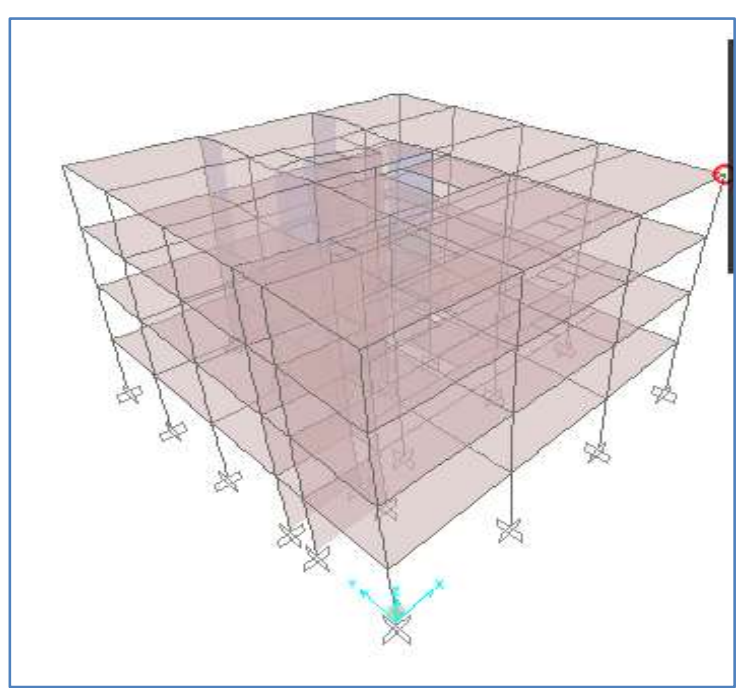

Fig-9: Deformation Shape of UBC for Frame and Shear Wall with Slab 


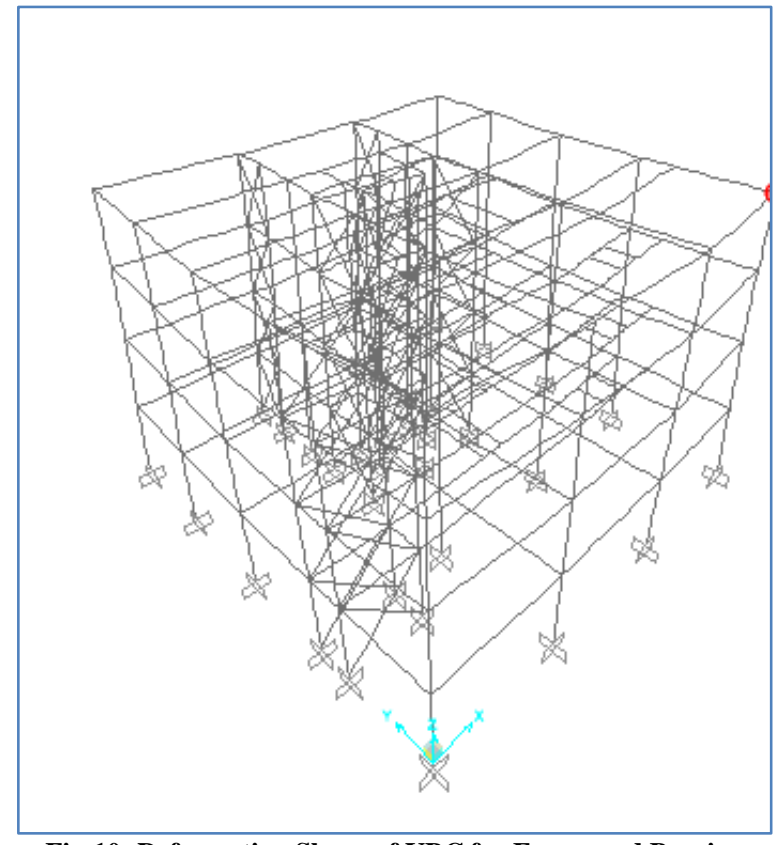

Fig-10: Deformation Shape of UBC for Frame and Bracing

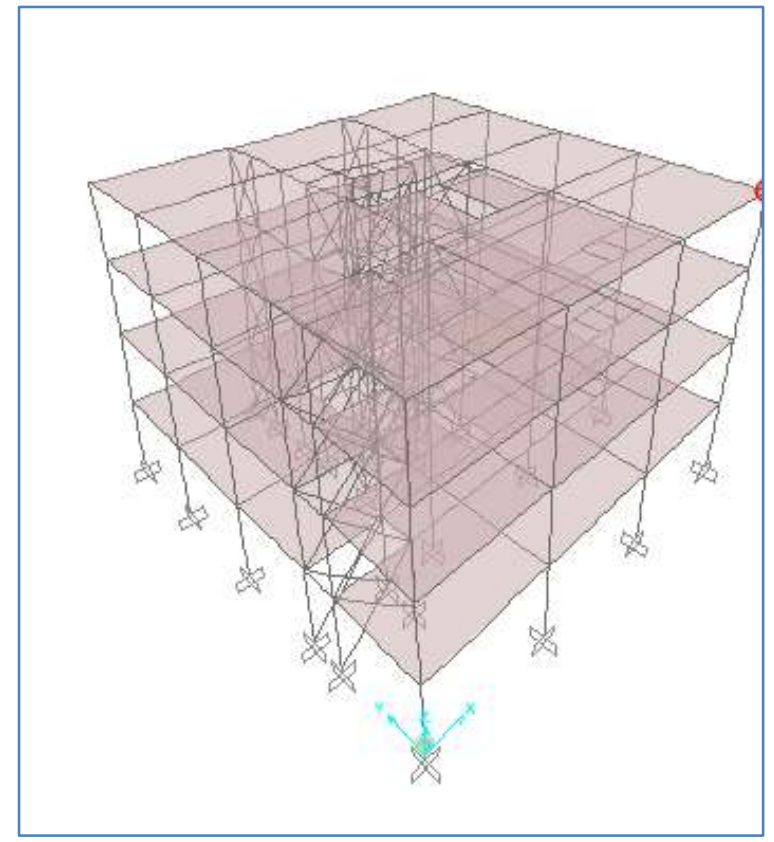

Fig-11: Deformation Shape of UBC for Frame and Bracing with Slab.

Table-1: Comparison Analysis between Deflections in Response Spectrum (UBC)

\begin{tabular}{|c|c|}
\hline Type & Deflection $(\mathbf{m m})$ \\
\hline Frame & 0.2778 \\
\hline Frame and Shear Wall & 0.0377 \\
\hline Frame and Shear Wall with Slab & 0.0309 \\
\hline Frame and Bracing & 0.0253 \\
\hline Frame and Bracing with Slab & 0.0141 \\
\hline
\end{tabular}

Table-2: Comparison of Results for Various Retrofitting Techniques.

\begin{tabular}{|c|c|c|c|c|c|}
\hline Modal & $\begin{array}{c}\text { Displacement } \\
(\mathbf{m m})\end{array}$ & $\begin{array}{c}\text { Time- history } \\
\text { in X-direction } \\
(\mathbf{m m})\end{array}$ & $\begin{array}{c}\text { Time- history } \\
\text { in Y-direction } \\
\mathbf{( m m})\end{array}$ & $\begin{array}{c}\text { Model } \\
\text { Analysis } \\
(\mathbf{m m})\end{array}$ & $\begin{array}{c}\text { BC } \\
\text { Analysis } \\
(\mathbf{m m})\end{array}$ \\
\hline Frame & 3.7 & 98 & 87 & 0.27 & 0.002 \\
\hline Frame and Shear Wall & 3.7 & 40 & 79 & 0.1 & 0.04 \\
\hline Frame and Shear Wall with Slab & 4.3 & 57 & 71 & 0.1 & 0.03 \\
\hline Frame and Bracing & 3.7 & 65 & 75 & 0.5 & 0.03 \\
\hline Frame and Bracing with Slab & 4.3 & 85 & 84 & 0.6 & 0.02 \\
\hline
\end{tabular}

\section{For Frame}

At joint 142 the deformation shape for frame is shown in Figure 7. Deflection (U3) is equal to 0.2778 $\mathrm{mm}$. The fundamental period is $0.59537 \mathrm{sec}$ and the frequency is $1.67962 \mathrm{~Hz}$.

\section{For Frame and Shear Wall}

At joint 142 the deformation shape for frame and shear wall is shown in Figure 8. Deflection (U3) is equal to $0.0377 \mathrm{~mm}$.

\section{For Frame and Shear Wall with Slab}

At joint 142 the deformation shape for frame and shear wall with slab is shown in Figure 9. Deflection (U3) is equal to $0.0309 \mathrm{~mm}$.

\section{For Frame and Bracing}

At joint 142 the deformation shape for frame and bracing is shown in Figure 10. Deflection (U3) is equal to $0.0253 \mathrm{~mm}$.

\section{For Frame and Bracing with Slab}

At joint 142 the deformation shape for frame and bracing with slab is shown in Figure 11. Deflection (U3) is equal to $0.0141 \mathrm{~mm}$.

\section{Comparison between the models}

The maximum deflection at shear wall is $0.0377 \mathrm{~mm}$. The results of dynamic analysis for the models are shown in Table 1. Table 2 shows a comparison of results for various retrofitting techniques. 


\section{CONCLUSIONS}

The SAP2000 results show an exact comparison with the independent results. Deflections, shear forces and moments of beams and columns were obtained by SAP2000 for the four-storey residential reinforced concrete building. All results were static results of analysis and design for the building without slabs and with slabs.

Study showed that, for both beams and columns in cases with and without slabs, the maximum values of shear forces, moments and deflections were decreased at same distance. The results of maximum moment and minimum moment of slabs in long direction (X-axis) were larger than those relevant results in short direction ( $\mathrm{Y}$-axis).

As a result of the dynamic analysis of the three methods of analysis, which are Modal Analysis (Modal 1-7), Time-history Analysis, and Response-spectrum Analysis (UBC) described in Table 2, it was found that the results of the building in case of shear wall is better than the case of bracing in cases of Time-history Analysis (see Figure 10) and Modal Analysis "Modal 17"' (see Figure 11).

\section{REFERENCES}

1. Alluqmani, A. E. (2013a). Flexural and Shear Behaviour of Wide RC Beams'. The Civil Engineering $\mathrm{PhD}$ Conference, University of Strathclyde, Glasgow, Scotland-UK. 30 October.

2. Alluqmani, A. E., (2013b). Development of Detailing and Design Models for Wide Concrete Beams'. The Engineering RPD Conference, University of Strathclyde, Glasgow, Scotland-UK. 27 June 2013. 13 pp, with "Proposed Detailing and Design Models for Wide RC Members" and "The Structural Design and Behaviour of Wide RC Beams".

3. Alluqmani, A. E., \& Saafi, M. B. (2014). Structural Reinforced Concrete Beams in Shear. The 2014 SSC-07 Conference, University of Edinburgh, Edinburgh, Scotland-UK. ISBN 9780956904522, Session 11: Engineering, Paper No. ENG 506. 1-2 February 2014. 6.

4. Khan, I., Shan, D., \& Bhatti, A. (2014). Temperature Effect Analysis of Viscoelastic Damper and Magnetorheological Damper for Vibration Control of Stayed-Cable, Bridge
Maintenance, Safety, Management and Life Extension, 2167-2175.

5. Bhatti, A.Q. (2016). Application of Dynamic Analysis and Modelling of Structural Concrete Insulated Panels (SCIP) for Energy Efficient Buildings in Seismic Prone Areas. Elsevier Journal of Energy and Building, 128, 164-177.

6. Bhatti, A. Q. (2015). Falling-weight impact response for prototype RC type rock-shed with sand cushion. Materials and Structures, 48(10), 3367-3375.

7. SBC. (2007). "Saudi Building Code Requirements”, 301,304, 2007. Structural Loading and Forces.

8. Alam, Z., Haider, A., \& Bhatti, A. Q. (2013). Seismic Evaluation and Retrofit of Existing building in Islamabad.

9. Bhatti, A. Q., Hassan, S. Z. U., Rafi, Z., Khatoon, Z., \& Ali, Q. (2011). Probabilistic seismic hazard analysis of Islamabad, Pakistan. Journal of Asian Earth Sciences, 42(3), 468-478.

10. Bhatti, A. Q. (2013). Performance of viscoelastic dampers (VED) under various temperatures and application of magnetorheological dampers (MRD) for seismic control of structures. Mechanics of Time-Dependent Materials, 17(3), 275-284.

11. Federal Emergency Management Agency. (1997). NEHRP guidelines for the seismic rehabilitation of buildings. Reporte FEMA 273.

12. Council, A. T. (1996). Seismic evaluation and retrofit of concrete buildings. Report No. SSC 9601: $A T C-40,1$.

13. Mosalam, K. M., Takhirov, S. M., \& Hashemi, A. (2009). Seismic evaluation of 1940s asymmetric wood- frame building using conventional measurements and high- definition laser scanning. Earthquake engineering \& structural dynamics, 38(10), 1175-1197.

14. Takhirov, S. (2010). Laser scanners in structural assessment and finite element modeling. In Structures Congress 2010 (pp. 2226-2237).

15. Monterey, C. (2013). Blach Construction Company, 2013. Seismic Retrofit and Restoration of the Historic Carmel Mission Basilica, 220 Year Old Structure, a National Historic Landmark using 3D Laser Scanning, Blach Cooperation, San Jose, San Francisco, California, July 2013. http://www.blach.com/news/july-24-2013/blachcompletes-retrofit-carmel-mission-basilica. 